\title{
Usulan Perbaikan untuk Mengurangi Pemborosan dengan Pendekatan Lean Six Sigma
}

\author{
Yuli Setyaningsih ${ }^{1}$, Dwi Nurul Izzhati ${ }^{2}$, Jazuli ${ }^{3}$ \\ Teknik Industri, Fakultas Teknik, Universitas Dian Nuswantoro \\ JI. Nakula I No.5-10, Semarang \\ Jawa Tengah 50131 \\ Email : 512201500839@mhs.dinus.ac.id¹, dwi.nurul.izzhati@dsn.dinus.ac.id², \\ jazuli@dsn.dinus.ac.id ${ }^{3}$
}

\begin{abstract}
PT. PKM is a company engaged in the germant industry. In the production process there are problems related to waste that related to waste that causes the production target not being achieved in Oktober-November 2018 as many as 109, 414 pcs and only able to produce as much as 84,111 pcs. There fore solution with Lean Six Sigma was used consists of: 1). The define phase obtained three wastes including a defect of 13,121 pcs, an idle time of 794 seconds, and a total reworking of 577 seconds for 60 pcs of product rework. 2). Measure Phase in addition, there is also a line balancer efficiency value of $43.96 \%$ and a balance delay of $56 \%$. 3). The analysis phase is carried out an analysis of the causal factors towards the type of stich jump and the type of idle bottleneck. The improvement phase is done by designing a new production line using the Line Balancing method and arena simulation that requires improvement with the number of stations reduced from 36 to 20 work stations balancing line efficiency to $79.12 \%$, delaying the balance up to $21 \%$, the number of outputs increasing from 137 pcs to 216 pcs, and bottlenecks decreased from $36 \%$ to $2.7 \%$.In the control carried out to help smooth the design of new lines, namely by regulating the cycle time, arrival time and the number of entities, and the number of worker.
\end{abstract}

Keywords: Waste, Lean Six Sigma, Line Balancing, Balance Delay

\begin{abstract}
Abstrak
PT. PKM merupakan perusahaan yang bergerak dalam industri garmen. Dalam sistem produksinya terdapat permasalahan terkait pemborosan yang menyebabkan tidak tercapainya target produksi pada bulan Oktober-November 2018 sebanyak 109.414 pcs, dan hanya mampu memproduksi sebanyak 84.111 pcs. Maka dicari solusi dengan pendekatan Lean Six Sigma, yang terdiri: 1). Tahap define diperoleh tiga pemborosan antara lain defect sebanyak $13.121 \mathrm{pcs}$, idle time sebesar 794 detik, dan total rework sebesar 577 detik untuk 60 pcs produk rework. 2) Tahap measure didapatkan jenis cacat dominan yaitu jump of stich dan jenis idle dominan yaitu bottleneck. Selain itu juga diketahui nilai line balancing eficiency sebesar $43,96 \%$ dan balance delay 56\%. 3) Tahap analyze dilakukan analisis faktor penyebab terhadap jenis cacat jump of stich dan jenis idle bottleneck. 4). Tahap improve dilakukan perancangan lini produksi baru dengan metode Line Balancing dan simulasi arena didapatkan kondisi perbaikan dengan jumlah stasiun turun dari 36 menjadi 20 stasiun kerja line balancing efficiency menjadi $79,12 \%$, balance delay turun menjadi $21 \%$, jumlah output meningkat dari 137 pcs menjadi 216 pcs, dan bottleneck menurun dari $36 \%$ menjadi $2,7 \%$. Pada tahap control dilakukan untuk membantu kelancaran perancangan line baru, yaitu dengan mengontrol waktu siklus, waktu kedatangan dan jumlah entitas, serta jumlah tenaga kerja.
\end{abstract}

Kata kunci: Pemborosan, Lean Six Sigma, Line Balancing, Balance Delay 


\section{Pendahuluan}

Pertumbuhan industri manufaktur saat ini sedang mengalami kemajuan yang sangat pesat, khususnya industri garmen. Besarnya permintaan pasar akan pakaian jadi secara global, membuat pebisnis industri garmen dituntut untuk menghasilkan produk dengan kualitas terbaik. Proses yang dikerjakan dengan baik dan sesuai dengan standar yang ditentukan akan menghasilkan kualitas yang baik pula [1]. Standar kualitas yang dimaksud adalah bahan baku, proses produksi dan bahan jadi [2].

Dalam menghasilkan produk yang berkualitas, terkadang perusahaan masih menjumpai permasalahan. Masalah yang sering terjadi dalam perusahaan terkait dengan kualitas produksi salah satunya ditandai dengan adanya pemborosan pada lantai produksi yang menyebabkan target produksi tidak tercapai. PT. PKM merupakan salah satu industri garmen yang berada di Semarang, target produksi pada bulan Oktober hingga November 2018 terjadi pemborosan karena hanya berhasil diproduksi sebesar 84.111 pcs dari target produksi sebesar 109.414 pcs. Pemborosan yang dimaksud diantaranya cacat produk (defect), idle time, dan over processing. Selain dilihat dari adanya pemborosan, level sigma juga ikut menentukan tingkat kualitas pada perusahaan. Untuk saat ini, perusahaan berada pada level 3,49 sigma. Data defect setiap stasiun dapat dilihat pada tabel berikut:

Tabel 1 Persentase Reject Tiap Stasiun Tahun 2018

\begin{tabular}{|l|l|l|}
\hline Stasiun & $\begin{array}{l}\text { Total Reject } \\
\text { (pcs) }\end{array}$ & Reject\% \\
\hline Gudang Material & 65223 & 3,63 \\
\hline Cutting & 55667 & 3,10 \\
\hline Sewing & 192201 & 10,69 \\
\hline Finishing & 20091 & 1,12 \\
\hline
\end{tabular}

Berdasarkan tabel 1 diatas diketahui bahwa data reject terbesar adalah pada stasiun sewing dengan total 192201 pcs dan persentase reject sebesar 10,69\%. Persentase reject yang dapat diterima oleh perusahaan adalah $10 \%$.

Pemborosan selanjutnya adalah idle time. Pemborosan tersebut dipicu karena adanya ketidakseimbangan beban kerja. Ketidakseimbangan beban kerja juga menyebabkan tingginya defect pada proses operasi. Total Idle time yang didapatkan dari hasil pengamatan adalah sebesar 794 detik. Berkaitan dengan idle time, salah satu jenis idle yang sangat bepengaruh menimbulkan waktu menganggur adalah adanya penumpukan (bottleneck).

Pemborosan lainnya adalah adanya over processing yaitu kegiatan yang tidak memberikan nilai tambah bagi perusahaan maupun customer. Pemborosan ini harus segera dihilangkan karena dapat berdampak pada pemborosan waktu. Di PT. PKM, proses tersebut ditandai adanya rework yang sering dilakukan oleh pekerja. Total rework pada tahun 2018 adalah sebanyak adalah sebanyak 4.538 pcs produk rework.

Dari permasalahan yang telah dipaparkan diatas, dibutuhkan suatu metode pengendalian yang mampu mengeliminasi pemborosan (waste) tersebut. Pendekatan yang mungkin dilakukan adalah penerapan Lean Six Sigma. Pendekatan Lean Six Sigma diartikan sebagai integrasi dari pendekatan Lean dan Six Sigma. Pendekatan Lean Six Sigma berfungsi untuk mengidentifikasi dan menghilangkan waste berupa cacat produk, over processing, dan idle time pada lantai produksi.

\section{Metode Penelitian}

Kualitas ialah kondisi dimana adanya hubungan yang dinamis pada produk, jasa, manusia, proses serta lingkungan yang harapannya dapat memenuhi atau melebihi keinginan [3]. Sebuah produk dikatakan berkualitas tinggi apabila karakteristik yang dimiliki dapat selaras dengan keinginan serta kebutuhan konsumen dalam pasar. Menurut Purponi dan Andesta [4], kecilnya tingkat variabilitas output dapat menghasilkan produk yang berkualitas.

Pengendalian kualitas adalah suatu tindakan yang sengaja dilakukan agar kualitas produk atau jasa perusahaan dapat dijaga, diarahkan serta dipertahankan sesuai dengan perencanaan awal yang telah ditetapkan [5]. 


\section{Define}

Merupakan tahapan dimana dilakukan tindakan untuk mengetahui proses apa saja yang ada pada stasiun sewing.

\section{a. Identifikasi Waste}

pada penelitian ini, identifikasi waste dilakukan dengan cara melakukan memberikan penilaian terhadap tujuh variabel waste yang dilakukan oleh staff bagian produksi dengan skala 0-2. Nilai 0 artinya jarang terjadi, nilai 1 artinya kadang-kadang terjadi, dan nilai 2 artinya sering terjadi.

b. Value Stream Mapping (VSM)

VSM ialah alat perbaikan yang bertujuan untuk membantu merealisasikan proses produksi secara keseluruhan yang menampilkan aliran material juga aliran informasi.

\section{c. Identifikasi Jenis Cacat}

Identifikasi jenis cacat dilakukan untuk mengetahui jenis cacat apa aja yang ada pada lantai produksi khusunya bagian sewing.

d. Penentuan Nilai Idlle

Idle time adalah waktu tunggu atau waktu yang tidak produktif dimana seorang karyawan tidak bekerja dikarenakan faktor-faktor diluar kendali perusahaan. Nilai idle time didapatkan dari pengamatan langsung pada bagian produksi khususnya stasiun sewing PT. PKM.

e. Identifikasi Jenis Idle

Identifikasi jenis kegiatan idle bertujuan untuk mengetahui aktivitas idle apa saja yang ada pada lantai produksi khususnya bagian sewing.

\section{Measure}

Measure ialah tahapan dimana ukuran ukuran kunci didefinisikan dan data dikumpulkan, disusun dan disajikan.

a. Diagram Pareto

Pembuatan diagram pareto berguna untuk mengetahui jenis defect apa yang paling berpengaruh terhadap kegagalan produk. Urutan pembuatan diagram pareto adalah :

1. Mengidentifikasi penyebab masalah kemudian melakukan pengumpulan data.

2. Membuat daftar yang berisikan frekuensi kejadian masalah yang sedang diteliti.

3. Mengurutkan frekuensi kejadian tersebut dari besar ke kecil dan menghitung frekuensi kumulatif serta presentasenya.

4. Membuat histogram berdasarkan frekuensi kejadian yang telah diurutkan.

\section{b. Line Balancing Efficiency}

Line balancing efficiency adalah rasio antara total waktu stasiun kerja dibagi dengan cycle time dikalikan jumlah stasiun kerja.

Line Balancing Efficiency $=\frac{\sum_{k=1}^{k} S T_{k}}{K, C T} \times 100 \%$

Balance Delay $=\frac{(K . C T)-(\Sigma S T i)}{(K)(C T)} \times 100 \%$

\section{Keterangan:}

$$
\begin{array}{ll}
\bar{K} & =\text { jumlah stasiun kerja } \\
C T & =\text { waktu siklus } \\
S T_{k} & =\text { waktu stasiun kerja dari ke-1 }
\end{array}
$$

3. Analyze

Pada tahapan ini analyze, yaitu melakukan verifikasi data untuk membuktikan akar masalah yang terjadi.

a. Analisis Value Stream Mapping

Analisis VSM digunakan untuk mengetahui hasil analisis dari VSM yang ada di tahap define.

b. Analisis Diagram Pareto

Diagram pareto menunjukkan jenis idle yang paling tinggi dan jenis reject paling dominan muncul.

c. Analisis Line Balancing Efficiency Analisis line balancing efficiency menunjukkan berapa nilai line balancing efficiency saat ini. 
d. Diagram Sebab Akibat

Diagram sebab akibat digunakan untuk mengidentifikasi akar penyebab masalah kedalam 5 kategori yaitu: a) manusia, b) mesin, c) lingkungan, d) cara kerja, dan e) material.

\section{Improve}

\section{a. Line Balancing}

Line balancing digunakan untuk meminimalisir idle time pada seluruh stasiun kerja, meminimalkan total stasiun kerja serta melakukan penyeimbangan lintasan dengan pembagian tugas kerja secara merata. Hartini [6], mengatakan ada beberapa metode heuristik diantaranya: a) Region Approach (RA), b) Largest Candidate Rule (LCR), c) Ranked Position Weight (RPW), dan d) Moodie Young (MY).

\section{b. Arena}

Arena adalah sebuah program penyusun model dan juga merupakan simulator. Langkahlangkah model simulasi dengan arena:

1. Membuat model

2. Perbaiki model

3. Lakukan simulasi terhadap model

4. Analisa hasil simulasi

\section{Control}

Pada tahap control akan dilakukan kegiatan yang dapat membantu kelancaran perancangan line baru. Tahap control ini dilakukan untuk mengontrol bottleneck agar stabil atau tidak meningkat pada simulasi arena. Control yang dilakukan adalah: a) Melakukan kontrol terhadap waktu siklus operasi atau stasiun kerja. b) Melakukan kontrol terhadap waktu kedatangan dan jumlah entitas. C) Melakukan kontrol terhadap jumlah tenaga kerja.

\section{Implementasi Lean Six Sigma}

Lean Six Sigma adalah upaya pengkombinasian konsep Lean dan Six Sigma yang didefinisikan sebagai suatu filosofi bisnis, pendekatan sistematik untuk mengidentifikasi dan menghilangkan pembrorosan atau aktivitas yang tidak bernilai tambah melalui peningkatan terusmenerus untuk mencapapai tingkat kinerja enam sigma, dengan cara mengalirkan produk (material, work-in-process, output) dan informasi menggunakan sistem tarik (pull system) dari pelanggan internal dan eksternal untuk mengejar keunggulan dan kesempurnaan dimana hanya ada 3,4 cacat dalam satu juta kesempatan atau operasi [7]. Bebarapa langkah berikut bisa dijadikan acuan untuk implementasi Lean Sigma dalam industri manuaktur.

1. Identifikasi nilai produk manufaktur yang akan ditawarkan kepada pelanggan berdasarkan perspektif pelanggan.

2. Transformasikan nilai-nilai persyaratan yang telah disepakati bersama diatas kedalam CTQ (Critical To Quality), CTC (Critical To Cost), CTD (Critical To Delivery), CTS (Critical To Service/Safety) agar dapat diukur, dipantau, dan dikendalikan oleh manajemen perusahaan.

3. Lakukan pemetaan produk individual, kelompok produk, atau lini produk sepanjang value stream process, untuk mengidentifikasi aktivitas bernilai tambah dan bukan nilai tambah yang merupakan pemborosan.

4. Tentukan beberapa kinerja kunci (key performance measures) value stream process pada saat sekarang sebagai berikut:

$$
\text { Process Cycle Efficiency }(\mathrm{PCE})=\frac{\text { Value Add Time }}{\text { Total Lead Time }}
$$

$$
\text { Lead Time }(\mathrm{LT})=\frac{\text { Amount of } \text { Work } \text { In Process }}{\text { Average } \text { Completed Rate }}
$$

5. Desain value stream process map untuk masa mendatang beserta target untuk meningkatkan PCE melalui rasionalisasi proses dan eliminasi E-DOWNTIME waste, reduksi cacat, menurunkan lead time melalui penurunan work-in-process inventory dengan jalan penyeimbangan proses, dan peningkatan QCSDM (quality, cost, service/safety, delivery, morale).

6. Untuk meningkatkan kinerja proses tersebut, dapat menerapkan berbagai alat dan teknik Lean-Sigma, mulai dari teknik-teknik sederhana seperti: 6S (Sort, Stabilize, Shine, 
standardisze, Safety, Sustain) sampai teknik-teknik lanjutan seperti: Vendor Managed Inventory (VMI), Design Of Experiments (DOE), dll.

\section{Hasil dan Analisis}

Hasil dan analisis dari penelitian ini dilakukan sesuai tahapan penelitan.

\subsection{Pengumpulan Data}

Data yang dikumpulkan dalam penelitian ini adalah:

\section{a. Data Jumlah Produksi}

Data yang digunakan adalah data jumlah produksi harian jaket style 3422 pada bulan Oktober sampai November 2018. Total keseluruhan jaket yang diproduksi selama kurun waktu tersebut adalah sebesar 52.582 pcs. Jumlah produksi terbesar terdapat pada line 10 yaitu sebesar 9.744 pcs.

\section{b. Waktu Proses}

Data waktu proses yang digunakan pada penelitian ini adalah data waktu setiap operasi di line 10 bagian sewing. Berdasarkan tabel 2, dapat diketahui bahwa jumlah proses pada line 10 pembuatan jaket style 3422 bagian sewing sebanyak 36 proses operasi. Rata-rata waktu operasi terbesar terdapat pada proses ke 24 sebesar 239 detik yaitu pasang manset lengan.

Tabel 2 Data Waktu Proses

\begin{tabular}{|c|c|c|c|c|c|c|c|}
\hline \multirow[t]{2}{*}{ No. } & \multirow[t]{2}{*}{ Proses } & \multicolumn{5}{|c|}{$\begin{array}{l}\text { Waktu Pengamatan ke- } \\
\text { (detik) }\end{array}$} & \multirow{3}{*}{$\begin{array}{c}\text { Rata- } \\
\text { Rata } \\
64\end{array}$} \\
\hline & & 1 & 2 & 3 & 4 & 5 & \\
\hline 1 & Pasang lapisan dalam kantong & 62 & 65 & 68 & 60 & 65 & \\
\hline 2 & Pasang cnc lapisan kantong & 28 & 30 & 30 & 32 & 30 & 30 \\
\hline 3 & Pasang ziper ke lapisan kantong + icik & 149 & 140 & 138 & 135 & 145 & 141 \\
\hline 4 & Pasang lapisan kantong 1 ke body & 121 & 115 & 110 & 108 & 110 & 113 \\
\hline 5 & Pasang lapisan kantong 2 & 107 & 110 & 100 & 100 & 105 & 104 \\
\hline 6 & Papras kantong depan (jadi) & 99 & 100 & 95 & 98 & 87 & 96 \\
\hline 7 & Pasang panel bodi depan + jahit bantu & 163 & 153 & 165 & 157 & 160 & 160 \\
\hline 8 & Papras panel body depan & 58 & 54 & 55 & 55 & 55 & 55 \\
\hline 9 & Pasang strip ke lengan depan atas & 81 & 78 & 80 & 86 & 80 & 81 \\
\hline 10 & Pasang strip ke lengan belakang atas & 62 & 60 & 68 & 60 & 65 & 63 \\
\hline 11 & Papras lengan belakang atas & 25 & 24 & 24 & 23 & 25 & 24 \\
\hline 12 & Stick lengan belakang + sambung + icik & 67 & 60 & 67 & 63 & 65 & 64 \\
\hline 13 & Pasang body belakang & 87 & 95 & 95 & 90 & 93 & 92 \\
\hline 14 & Pasang panel lengan atas ke body depan & 98 & 96 & 97 & 90 & 95 & 95 \\
\hline 15 & Pasang panel lengan bawah & 111 & 120 & 115 & 115 & 110 & 114 \\
\hline 16 & Sambung manset + balik & 45 & 49 & 50 & 47 & 45 & 47 \\
\hline 17 & Sambung krah & 34 & 37 & 36 & 33 & 35 & 35 \\
\hline 18 & Stick krah & 35 & 32 & 33 & 35 & 32 & 33 \\
\hline 19 & Runing krah & 50 & 54 & 50 & 55 & 53 & 52 \\
\hline 20 & Sambung dan pasang garasi zipper+stick & 120 & 130 & 128 & 125 & 120 & 125 \\
\hline 21 & Binding zipper & 72 & 80 & 74 & 80 & 75 & 76 \\
\hline 22 & Gosok zipper & 24 & 26 & 25 & 27 & 25 & 25 \\
\hline 23 & Sambung samping & 143 & 145 & 139 & 140 & 140 & 141 \\
\hline 24 & Pasang manset lengan & 240 & 238 & 238 & 241 & 238 & 239 \\
\hline 25 & Pasang krah + cekrik krah & 180 & 186 & 185 & 187 & 182 & 184 \\
\hline 26 & Piping krah & 141 & 145 & 148 & 145 & 140 & 144 \\
\hline 27 & Rimbas body bawah & 113 & 115 & 113 & 110 & 110 & 112 \\
\hline 28 & Pasang zipper + tutup zipper bawah & 163 & 158 & 165 & 160 & 162 & 162 \\
\hline 29 & Tutup zipper atas & 134 & 140 & 130 & 129 & 130 & 133 \\
\hline 30 & $\begin{array}{l}\text { Join krah + pasang size label + stick tape } \\
\text { leher }\end{array}$ & 136 & 126 & 120 & 130 & 125 & 7 \\
\hline 31 & Haming bawah & 243 & 235 & 240 & 230 & 235 & 237 \\
\hline 32 & Bartack kantong + rimbas body depan & 70 & 64 & 65 & 68 & 64 & 66 \\
\hline 33 & Stick zipper depan & 67 & 64 & 65 & 65 & 65 & 65 \\
\hline 34 & Haming krah + bathil & 107 & 110 & 107 & 100 & 110 & 107 \\
\hline 35 & Gosok & 204 & 210 & 210 & 200 & 205 & 206 \\
\hline 36 & QC & 175 & 160 & 165 & 170 & 169 & 168 \\
\hline
\end{tabular}




\section{c. Data jumlah cacat}

Data yang digunakan adalah data jumlah cacat produk jaket style 3422 yang diperoleh dari laporan jumlah cacat produk Oktober hingga November 2018.

Data perusahaan menunjukkan bahwa total data reject produk jaket selama bulan Oktober sampai November adalah sebesar 12.081 pcs. Data reject terbesar tedapat pada line 10 yaitu sebesar 3.544 pcs, sedangkan untuk data reject terendah tedapat pada line 9 yaitu sebesar 817 pcs.

\section{d. Data Rework}

Data yang digunakan adalah data rework pada lini produksi bagian sewing pembuatan jaket style 3422 selama Oktober-November tahun 2018, dalam sehari adalah sebanyak 60 pcs, dengan total waktu pengerjaan selama 6923 detik.

\subsection{Pengolahan Data}

Tahapan pengolahan data adalah:

\section{a. Define}

1. Identifikasi Waste

Tabel 3, menunjukkan bahwa waste yang sering terjadi adalah cacat produk (defect) dan waiting time dengan nilai 2 . Adapun waste yang kadang-kadang terjadi yaitu inappropriate processing dengan nilai 1.

Tabel 3 Identifikasi Waste

\begin{tabular}{|c|c|c|}
\hline No. & Jenis Waste & Staff Produksi \\
\hline 1 & Over Production & 0 \\
\hline 2 & Delays (Waiting Time) & 2 \\
\hline 3 & Excess Transportation & 0 \\
\hline 4 & Inappropriate Processing & 1 \\
\hline 5 & Unecessary Motion & 0 \\
\hline 6 & Unecessary Inventory & 0 \\
\hline 7 & Defective Product & 2 \\
\hline \multicolumn{3}{|c|}{ Sumber: Wawancara staff produksi, 2019 }
\end{tabular}

\section{Value Stream Mapping}

Value Stream Mapping merupakan gambaran dari proses produksi yang berlangsung dalam perusahaan, meliputi aliran informasi dan aliran material.

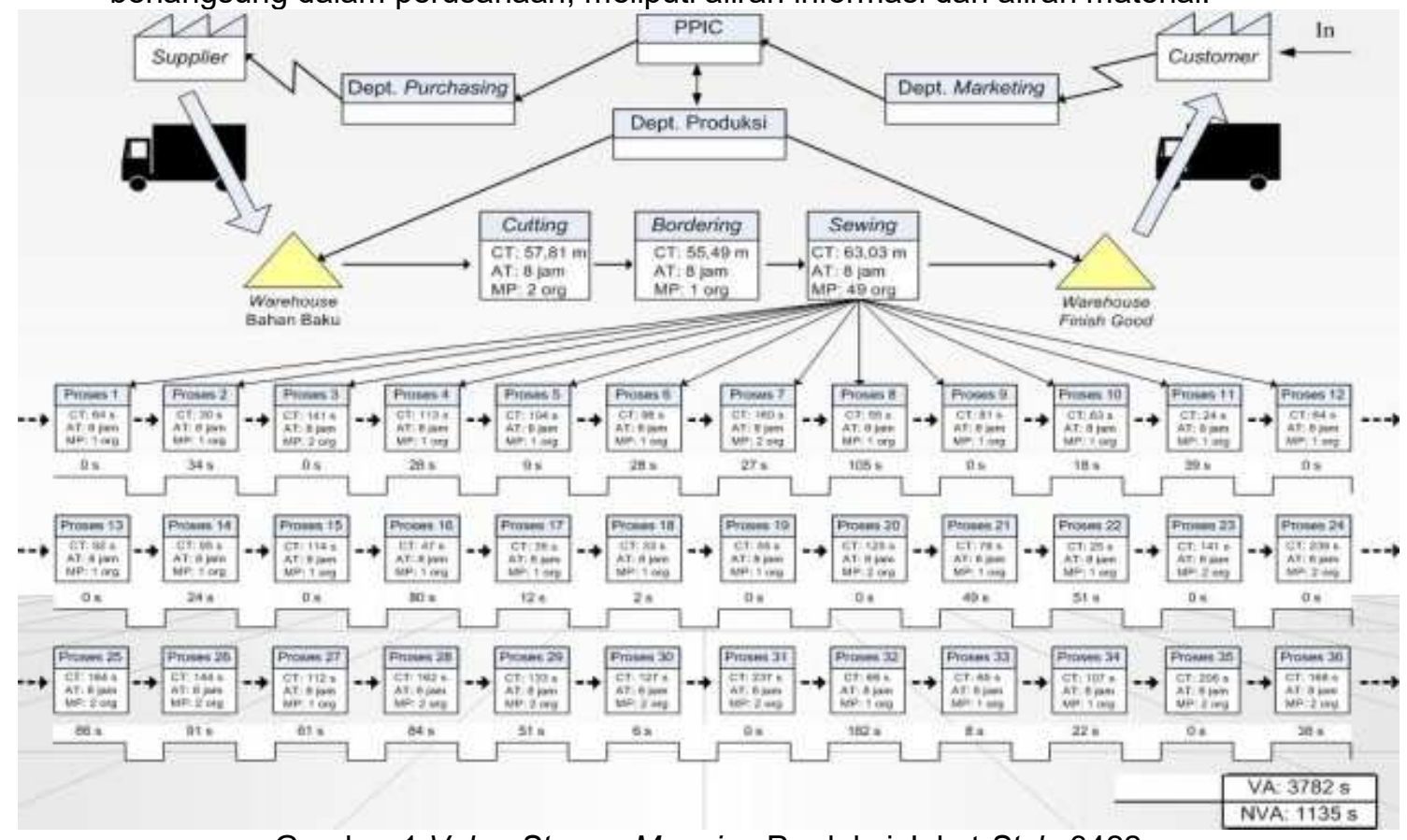

Gambar 1 Value Stream Mapping Produksi Jaket Style 3422 
Berdasarkan gambar 1, diatas dapat diketahui bahwa aktivitas value added pada pembuatan jaket style 3422 dalam satu kali produksi memiliki total waktu sebesar 3782 detik. Aktivitas non value added yang ditemukan adalah sebesar 1135 detik, dimana terdiri dari waktu menganggur sebesar 794 detik dan waktu pengerjaan ulang (rework) sebesar 341 detik. Total rework yang ditemukan dalam waktu satu hari sebanyak 5 pcs hingga 8 pcs produk rework. Proses sewing membutuhkan 49 operator dalam 8 jam kerja.

\section{Identifikasi Jenis Cacat}

Tabel 4 Identifikasi Jenis Cacat

\begin{tabular}{|c|l|l|}
\hline No & \multicolumn{1}{|c|}{ Jenis Defect } & \multicolumn{1}{c|}{ Definisi } \\
\hline 1 & BROKEN STICH & jahitan putus \\
\hline 2 & OPEN SEAM & jahitan melenceng \\
\hline 3 & RUN OF STICH & jahitan meleset \\
\hline 4 & UNEVEN STITCH & jahitan tidak rata/tidak lurus \\
\hline 5 & PLEAT & jahitan terlipat \\
\hline 6 & LABELLING & Label \\
\hline 7 & JUMP STICH & jahitan loncat \\
\hline 8 & LOOSE STICH & jahitan mengambang \\
\hline 9 & DIRT/SOIL & Kotor \\
\hline 10 & OIL & Berminyak \\
\hline
\end{tabular}

\section{Penentuan Idle Time}

Identifikasi jenis idle yang terjadi antara lain: Bottleneck, menunggu instruksi, tidak berada di area kerja, mengobrol, membetulkan mesin, menunggu kain di cutting, menoleh berlebihan, bertanya ke operator lain, berjalan-jalan ke gudang, menunggu waktu istirahat, dipakai sebagai dasar yang untuk menentukan idle time yang terjadi pada operasi kerja sesuai Tabel 5.

Tabel 5 Idle Time pada Operasi Kerja

\begin{tabular}{|c|c|}
\hline Operasi Kerja Ke- & Idle Time (detik) \\
\hline 2 & 34 \\
\hline 4 & 28 \\
\hline 5 & 9 \\
\hline 6 & 8 \\
\hline 8 & 105 \\
\hline 10 & 18 \\
\hline 11 & 39 \\
\hline 16 & 67 \\
\hline 17 & 12 \\
\hline 18 & 2 \\
\hline 21 & 49 \\
\hline 22 & 51 \\
\hline 25 & 55 \\
\hline 26 & 40 \\
\hline 27 & 32 \\
\hline 29 & 29 \\
\hline 30 & 6 \\
\hline 32 & 171 \\
\hline 33 & 1 \\
\hline 36 & 38 \\
\hline Total & 794 \\
\hline
\end{tabular}




\section{b. Meassure}

1. Diagram Pareto

Diagram pareto pada gambar 2, digunakan untuk mengetahui jenis kegiatan idle dan jenis cacat yang paling potensial menyebabkan terjadinya idle time dan kegagalan produk saat proses menjahit. Berdasarkan jenis defect paling besar adalah jump stich atau jahitan loncat. Hal itu ditandai dengan tingginya jumlah defect yaitu sebesar 2.787 pcs.

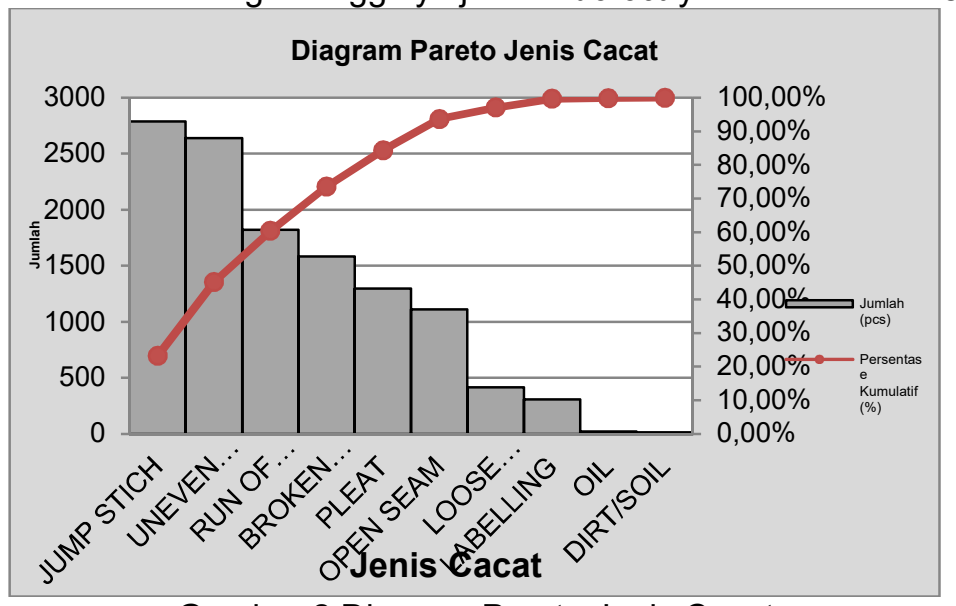

Gambar 2 Diagram Pareto Jenis Cacat

Berdasarkan Gambar 3. menunjukkan bahwa jenis kegiatan idle yang sering dilakukan adalah bottleneck. Hal tersebut ditandai dengan banyaknya frekuensi yaitu sebanyak 18 orang.

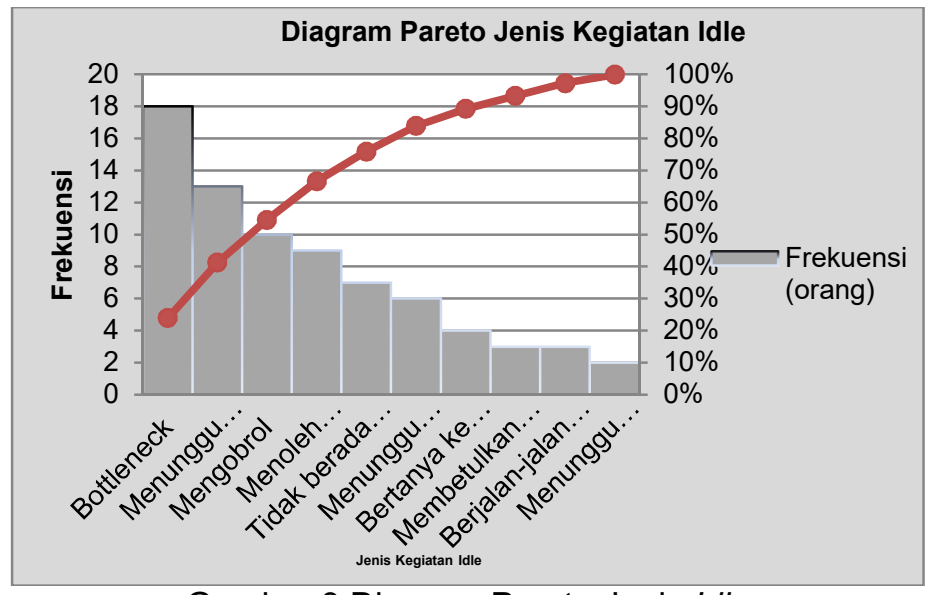

Gambar 3 Diagram Pareto Jenis Idle

\section{Line Balancing Efficiency}

Perhitungan Line Balancing Eficiency dilakukan untuk mengetahui tingkat efisiensi keseimbangan lini produksi. Berikut ini perhitungan Line Balancing Eficiency pada line 10:

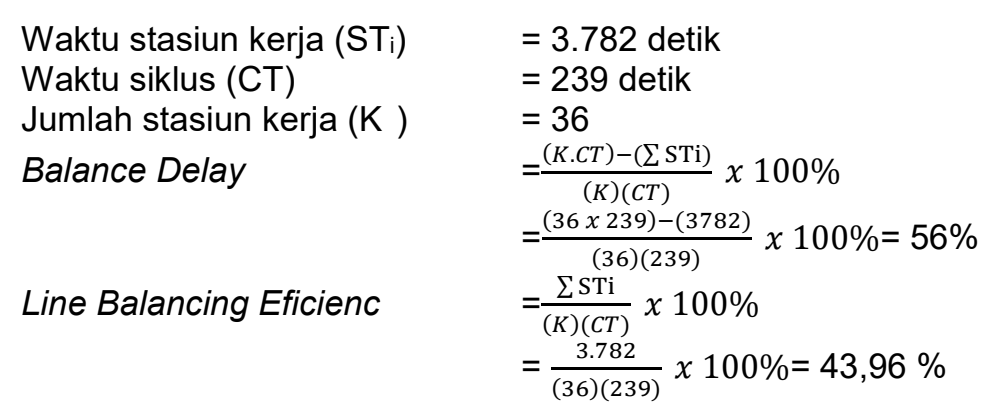


c. Analyze

1. Analisis Diagram Sebab Akibat

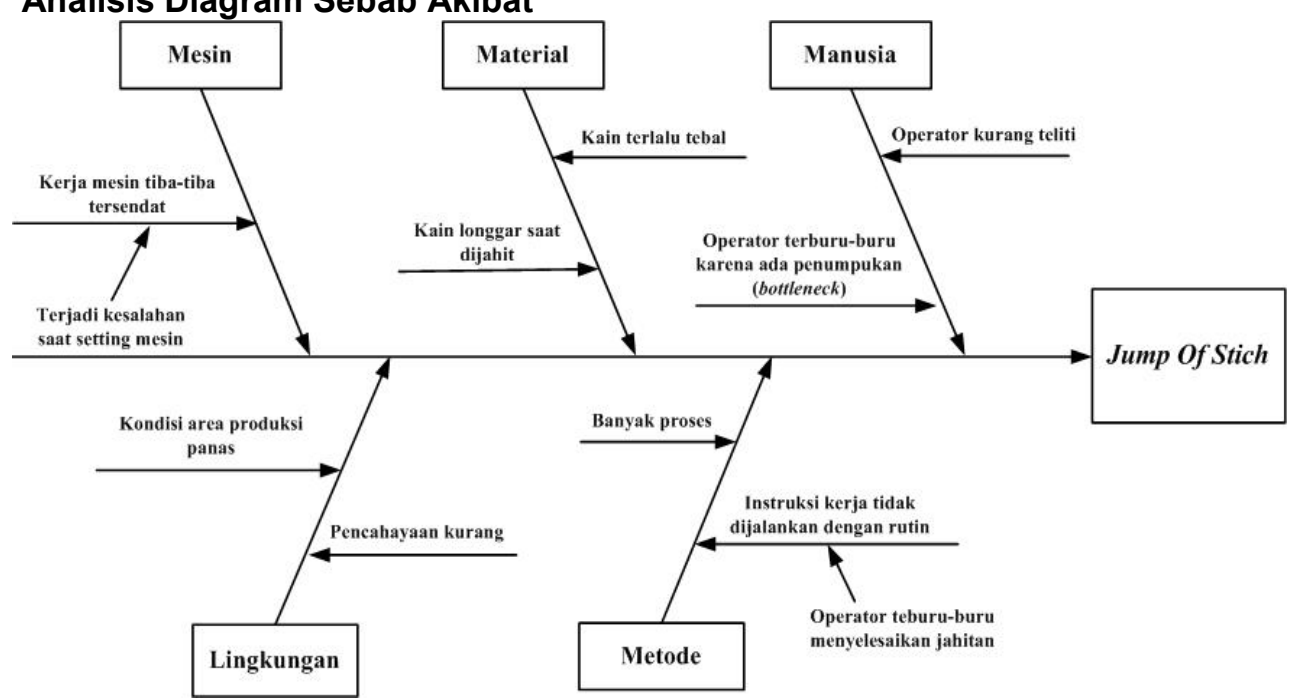

Gambar 4 Diagram Sebab Akibat Jump of Stich

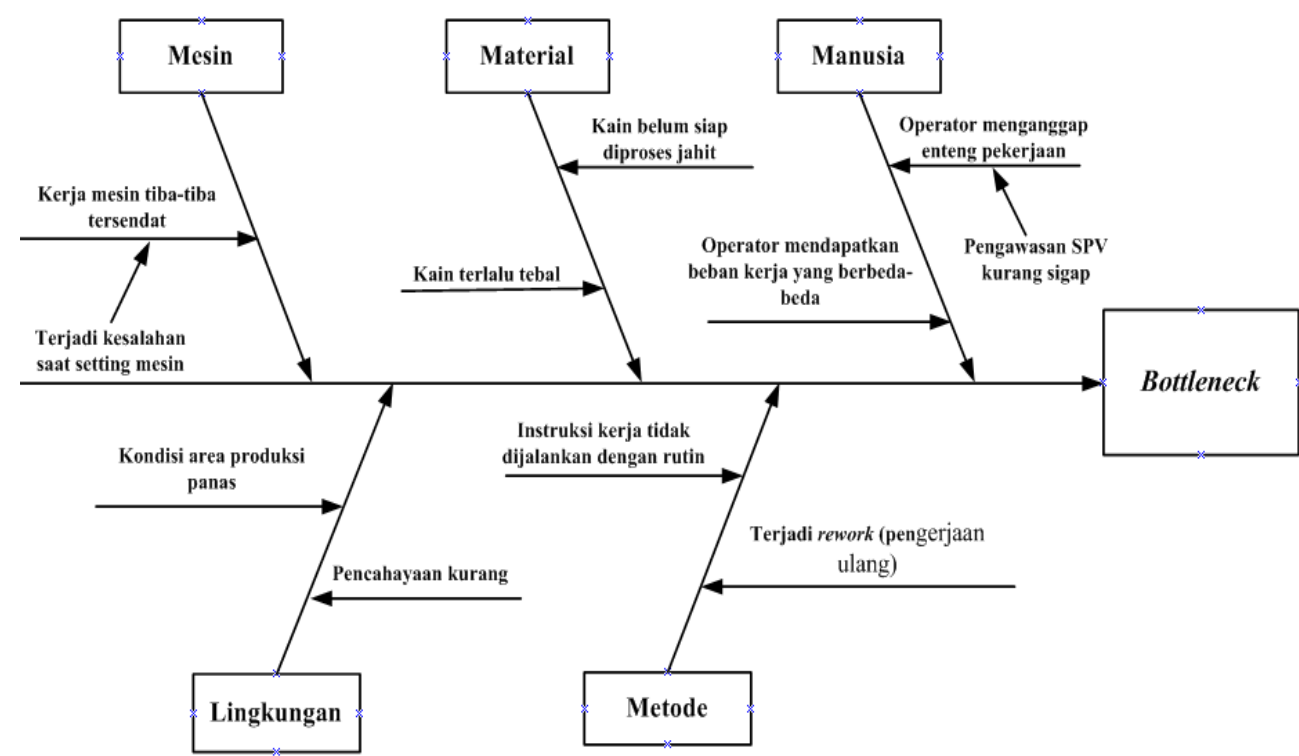

Gambar 5 Diagram Sebab Akibat Bottleneck

d. Improve

1. Melakukan perbaikan lini produksi dengan perhitungan line balancing efficiency dengan menggunakan metode Region Approach (RA) memiliki nilai line balancing efficiency paling besar yaitu $79,12 \%$ dan jumlah stasiun kerja 20 . Penggunaan metode RA mampu menaikkan nilai line balancing efficiency sebesar $35,16 \%$. Selain itu metode RA juga mampu menurunkan nilai balance delay sebesar $35 \%$, dimana kondisi aktual sebesar $56 \%$ turun menjadi $21 \%$.

2. Dengan menggunakan simulasi Arena, total output kondisi aktual berdasarkan simulasi dan kondisi nyata pada perusahaan sebesar 137 pcs, jumlah tersebut masih jauh dari target produksi harian yaitu sebesar 216 pcs. Hal tersebut dikarenakan terdapat penumpukan di beberapa stasiun, untuk itu perlu adanya perbaikan lini produksi agar output meningkat dan bottleneck berkurang. Persentase bottleneck didapatkan sebesar $36 \%$. Selanjutnya dengan simulasi arena. Total output kondisi perbaikan berdasarkan simulasi sebesar 210 pcs, jumlah tersebut mengalami kenaikan output sebesar 73 pcs dari kondisi aktual sebesar 137 pcs. Persentase bottleneck yang 
dihasilkan mengalami penurunan yaitu sebesar $33,3 \%$ dari kondisi aktual $36 \%$ menjadi $2,7 \%$.

3. Berdasarkan rekapitulasi perbandingan model kondisi aktual dan kondisi perbaikan, didapatkan jumlah output mengalami kenaikan sebesar 73 pcs. Bottleneck mengalami penurun dengan persentase $33,3 \%$. Line balancing efficiency yang didapat dari hasil perhitungan dengan metode Region Approach (RA) mengalami kenaikan sebesar $35,16 \%$. Balance delay mengalami penurunan sebesar $35 \%$. Setelah diadakan perbaikan, jumlah output meningkat dan bottleneck berkuramg. Kualitas produksi juga meningkat dikarenakan produk cacat berkurang. Berkurangnya produk cacat dikarenakan bottleneck mengalami penurunan. Proses rework juga berkurang karena produk cacat menurun.

4. VSM Perbaikan

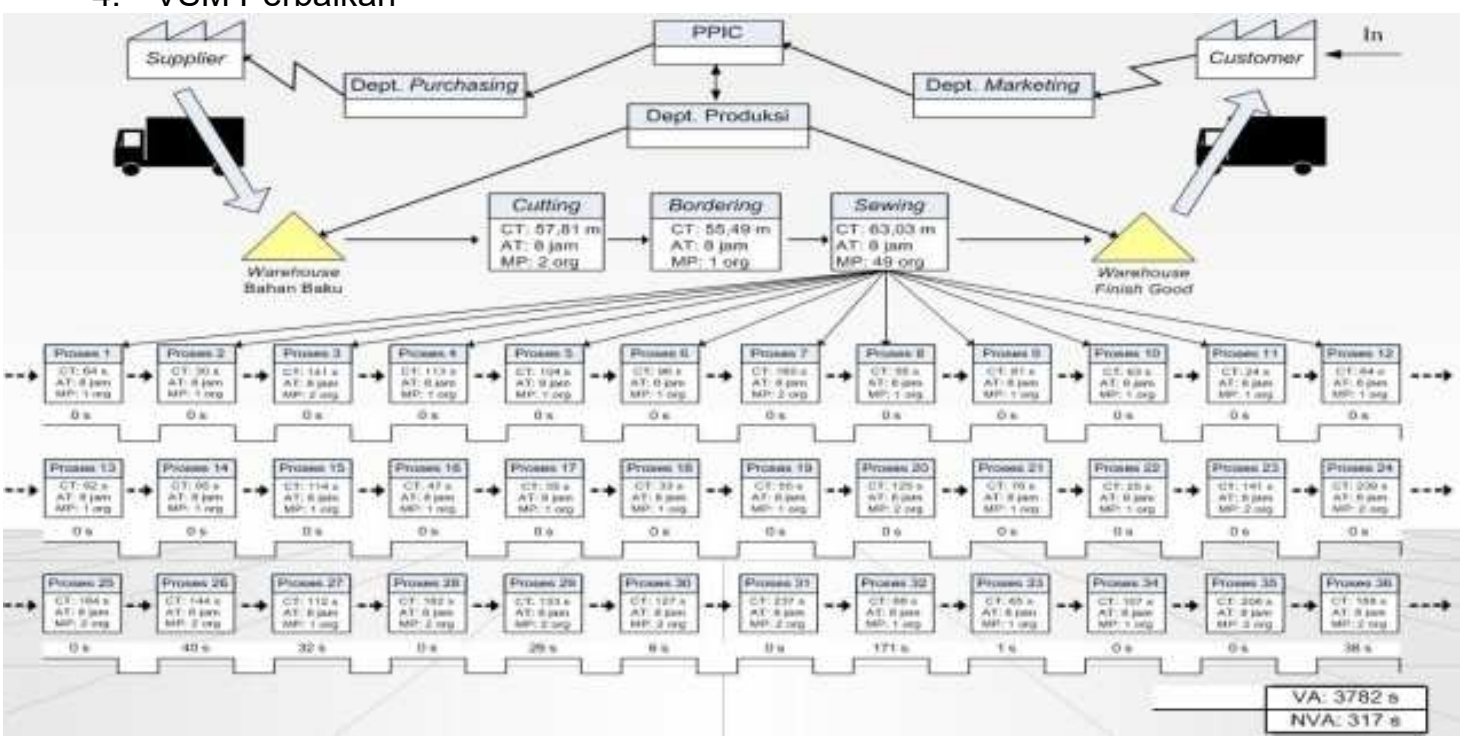

Gambar 6 Value Stream Mapping Rekomendasi Produksi Jaket Style 3422

\section{e. Control}

Merupakan tahapan terakhir dari DMAIC pada tools six sigma. Tujuan adanya control adalah untuk mengendalikan supaya bottleneck tidak meningkat lagi. Berdasarkan model simulasi yang telah dibuat, ada beberapa variabel yang harus dikontrol, diantaranya:

1. Waktu Siklus Tiap Operasi Kerja

Dalam hal ini waktu siklus digunakan untuk menggambarkan lamanya waktu proses untuk mengerjakan suatu produk. Apabila waktu siklus yang diinputkan terlalu besar, entitas akan mengalami penumpukan di beberapa proses atau stasiun kerja tertentu yang memiliki waktu siklus besar.

2. Waktu dan Jumlah Kedatangan

Waktu kedatangan merupakan waktu yang digunakan untuk menentukan kapan suatu bahan akan datang dan diproses. Jika waktu kedatangan terlalu cepat maka jumlah entitas yang dibawa juga semakin banyak, begitu pula halnya akan terjadi penumpukan apabila banyak entitas yang masuk dalam proses.

3. Jumlah Tenaga Kerja

Rekomendasi tenaga kerja yang diberikan adalah sebanyak 51 orang dari yang awalnya hanya 49 orang. Penambahan tenaga kerja diberikan pada proses operasi ke 24 yaitu pasang manset lengan sebanyak 2 orang, dikarenakan proses tersebut memiliki waktu proses paling besar. 


\section{Kesimpulan}

Berdasarkan hasil identifikasi dari pemborosan pada lantai produksi, didapatkan tiga pemborosan yang muncul dalam proses produksi khususnya bagian sewing. Ketiga pemborosan tersebut diantaranya produk cacat (defect), idle time, dan overprocessing (rework). Jumlah defect yang terhitung sebanyak 13.121 pcs, nilai idle time yang teridentifikasi sebesar 794 menit, dan total rework sebesar 60pcs. Jenis cacat produk yang paling dominan adalah Jump Of Stich atau jahitan loncat, sedangkan untuk kegiatan idle paling dominan adalah Bottleneck. Rancangan perbaikan lini produksi yang terpilih adalah metode RA dikarenakan nilai line balancing efficiency meningkat dari kondisi awal dari 36 menjadi 20 stasiun kerja, dan nilai balance delay sebesar $43,96 \%$ menjadi $79,12 \%$ setelah perbaikan. Jumlah stasiun kerja berkurang dari 36 menjadi 20 stasiun kerja, dan nilai balance delay menurun dari $56 \%$ menjadi $21 \%$. Validasi model simulasi arena kondisi perbaikan mengalami kenaikan output sebesar 73 pcs dari yang semula 137 pcs menjadi 210 pcs, untuk bottleneck mengalami penurunan sebesar $33,3 \%$ dari yang semula $36 \%$ menjadi $2,7 \%$. Selain itu kualitas produksi juga meningkat dengan turunnya produk cacat dan berkurangnya proses rework.

\section{Referensi}

[1] Darsono. (2013). Analisis Pengendalian Kualitas Produksi dalam Upaya Mengendalikan tingkat Kerusakan Produk. Jurnal Ekonomi Manajemen Akuntansi.

[2] Nasution, M., N. (2005). Manajemen Mutu Terpadu. Jakarta: Ghalia Indonesia.

[3] Goetsch D. L., S. B. Davis. (1994). Pengertian Kualitas. Jakarta: PT. Prenhalindo.

[4] Purponi P. \& D. Andesta. (2009). Integrasi Model Lean Six Sigma untuk Peningkatan Kualitas Produksi. Jurnal Teknik industri, 10 (2), 91-97.

[5] Ahyari, Agus. (1992). Pengertian Pengendalian Kualitas. Yogyakarta: BPFE Yogyakarta.

[6] Hartini. (2011). Teknik Mencapai Produksi Optimal. Bandung: CV Lubuk Agung.

[7] Gaspersz, V. (2007). Lean Six Sigma for Manufacturing and Service Industries. Jakarta: PT. Gramedia Pustaka Utama. 